\title{
Conhecimento disciplinar: (im)possibilidades do discurso sobre a problemática ambiental
}

\author{
Luciana Palharini ${ }^{1}$
}

resumo: Este ensaio apresenta a crise ambiental como um resultado do modo de vida da sociedade capitalista, que abrange os três "registros ecológicos" que constituem o ser humano: o do ambiente, o social e o da subjetividade, tal como é entendido por Félix Guattari. Realiza uma reflexão acerca das possibilidades do discurso sobre a problemática ambiental no contexto da produção do conhecimento na modernidade, a partir dos conceitos de discurso, disciplina, saber, verdade e poder desenvolvidos por Michel Foucault. Diante desses referenciais, apresenta algumas observações sobre a transversalidade do tema meio ambiente na educação, tal como foi adotada pelo MEC, indicando algumas impossibilidades dessa proposta. Por fim, propõe o conceito de Estado e máquina de guerra de Deleuze e Guattari para pensar algumas possibilidades para a educação ambiental.

palavras-chave: Discurso, Disciplina, Episteme.

abstract: This essay presents the environmental crisis as a result of the capitalist society's way of life. It adopts three "ecological registers" that compose the human being: the environment, the social relationships and the subjectivity, as it is understood by Félix Guattari. Studies about concepts as discourse, discipline, knowledge, truth and power developed by Michel Foucault were used to think of the possibilities of the discourse about the environmental problems considering how knowledge is produced in modernity. From this theoretical reference, it presents some views about how transversality is adopted by the MEC (Ministry of Education and Sports) and points some of its impossibilities. Finally, it offers a purpose

\footnotetext{
1 e-mail: luapalharini@gmail.com
} 
to think about some possibilities for environmental education from Deleuze and Guattari's concepts such as State and war machine.

keywords: Discourse, Discipline, Episteme.

\section{Introdução: alguns traços para configurar uma problemática ambiental}

Não faltam situações que nos deixem com a sensação de desconforto causada pelas conseqüências do modo de vida moderno. A promessa de bem-estar social, progresso econômico e liberdade plena a todos os cidadãos feita pelos defensores do modelo econômico capitalista traz consigo elementos bastante contraditórios. Os países ricos, que controlam $78 \%$ da produção e consomem $75 \%$ da energia disponível, representam apenas $21 \%$ da população no globo; a fome aumentou em 30\% nos países pobres; a distância entre esses e os países ricos e entre pobres e ricos em um mesmo país não pára de crescer (SANTOS, 2001). A temperatura global tem tido um aumento gradativo preocupante e os EUA, que, sozinhos, representam 25\% da taxa de emissão de gases industriais poluentes, recusam-se a assinar, em nome do progresso econômico da nação norte-americana, o Protocolo de Kyoto, que determina a redução de apenas $5,2 \%$ da emissão de gases.

O descaso frente à miséria, a postura de corrupção presente em todos os setores públicos em diversos países, a falta de liberdade física, psicológica e ideológica provocada pelo aumento das desigualdades sociais e pelo espírito de competição e exclusão, a degradação ambiental e as condições precárias de saúde e educação em muitos países deixam uma imensa parcela da população em condições de desconsolo e perda de referenciais.

Esse modelo de sociedade, cuja lógica principal é a do lucro e cuja bandeira é a do "progresso", independentemente das conseqüências geradas por ele, exclui igualmente seres vivos e situações que não se encaixem em suas regras de produção: os ciclos da natureza, o ritmo de trabalho próprio de cada indivíduo, etc. 
O modelo capitalista não teria se sustentado sem que o homem passasse a se enxergar fora da natureza e sem que essa tivesse sido objetificada - objeto a ser transformado, manufaturado em bens de consumo (VEIGA-NETO, 1994). A ciência moderna trabalha para a Revolução Industrial, que trabalha, desde então, para financiá-la. Tal casamento estende seus braços doutrinários para além das esferas econômicas e científico-acadêmicas. Segundo Edgar Morin (2001, p. 19), "a ciência tornou-se poderosa e maciça instituição no centro da sociedade, subvencionada, alimentada, controlada pelos poderes econômicos e estatais." Pouco a pouco na história, passamos da tirania da Igreja para a da Razão e a do Mercado.

Como afirma Guattari (2001, p. 10), vivemos hoje em uma época de "império de um mercado mundial que lamina os sistemas particulares de valor, que coloca num mesmo plano de equivalência os bens materiais, os bens culturais, os bens naturais, etc.”. A natureza para a sociedade capitalista tem valor de mercadoria, ela é importante para o homem somente na medida em que é conhecida por ele e representa alguma utilidade: trata-se de uma visão utilitarista da natureza (GRÜN, 2000). O homem ocidental capitalista não se vê dentro do mundo natural: este é visto apenas como um cenário sobre o qual ele se move e atua, controlando-o.

Nesse contexto de extrema valorização da técnica, no qual o objetivo de obtenção de lucro é inerente a toda atividade de nossa contemporaneidade, a crise ambiental se apresenta de forma singular na história. Essa singularidade, segundo Soffiati (2002), deve-se à combinação de seu caráter planetário e antrópico - visto que se trata de uma crise derivada de atividades humanas, sejam elas capitalistas ou socialistas, e visto que ambas têm em comum uma relação utilitarista e instrumentalizadora com a natureza.

O objetivo deste trabalho é estabelecer um diálogo com uma instância que, a meu ver, é de extrema importância a toda tentativa de discussão sobre as questões ambientais: a produção do conhecimento, tal como foi desenvolvida e consolidada pela sociedade moderna, e suas implicações para a discussão dos problemas ambientais dentro do território educacional, tendo em vista ainda que, apesar de não 
constituir uma disciplina específica, meio ambiente é sugerido pelas políticas educacionais atuais como tema transversal nos currículos do Ensino Fundamental. Para isso, deslocarei alguns conceitos de autores da Filosofia e da Educação que, embora tenham sido criados a partir de outras problemáticas, podem ser extremamente interessantes para que pensemos sobre os discursos do meio ambiente e a educação ambiental.

O primeiro deles é sobre o entendimento da crise ambiental como uma crise dos três registros ecológicos que constituem o ser humano: o do ambiente, o das relações sociais e o da subjetividade, tal como é entendida pelo filósofo Félix Guattari (2001). Assim, a problemática ambiental é apresentada como efeito colateral da sociedade moderna, não só como degradação ambiental, mas como crise da própria subjetividade humana e, conseqüentemente, das relações sociais. Entenda-se: do homem com a natureza não humana, do homem com outros homens e do homem com ele mesmo.

O segundo deles é o de tomar a discussão de Michel Foucault sobre a constituição dos saberes modernos, sobre o que o autor chama de episteme, como a configuração que um saber assume em um determinado período histórico e que lhe possibilita uma positividade enquanto saber. Para o autor, a disciplinaridade é um dos pilares da episteme moderna. Todo conhecimento produzido passa por esse crivo disciplinar. $O$ autor não elege apenas a disciplinaridade como constituinte da episteme moderna, mas é nela que focaremos nossa discussão acerca da produção de conhecimentos sobre o meio ambiente.

Por fim, deixo claro meu entendimento da educação como uma "área aberta", em contraposição a uma concepção que tenta lhe conferir um estatuto epistemológico próprio. A educação não seria, portanto, um território fechado, mas antes uma "terra de ninguém" e, conseqüentemente, também uma terra de todos, um território aberto e instável, que está em constante processo de territorialização/ desterritorialização/reterritorialização (GALLO, 2002, p. 278). A educação é um platô povoado por diversos campos de saber, que possibilitam diferentes olhares sobre os fenômenos educacionais e seus problemas. Além disso, entendemos que a educação, por ser uma 
prática social, é uma prática de subjetivação, ou seja, de produção de sujeitos, de subjetividades. Dessa maneira, minha preocupação se estabelece nas subjetividades produzidas em tempos de conhecimento disciplinar em relação aos problemas ambientais.

\section{Saber e poder, discurso e disciplina: contribuições de Michel Focault para pensar a produção do conhecimento na sociedade moderna}

A relação do homem com o mundo e, sobretudo, o conhecimento que é produzido sobre essa relação determinam uma postura ética frente ao mundo que orienta as ações humanas. As diferentes perspectivas de conhecimento determinam diferentes formas de apropriação do mundo e de inserção do homem na história.

Os problemas ambientais estão sendo cada vez mais importados por diversas disciplinas que constroem concepções muito variadas sobre a relação sociedade-natureza, direcionando a produção de saberes que orientam aplicações tecnológicas, atividades de planejamento e gestão urbanas, bem como práticas educativas, formais e não formais, que visam discutir as questões ambientais.

A produção do conhecimento, especialmente do conhecimento científico, nos parece uma questão importante na discussão sobre os problemas ambientais, seja na área da educação, seja em qualquer outro campo de saber.

Os discursos científicos, regidos por uma lógica capitalista, definem quadros de interpretação da problemática ambiental e, conseqüentemente, posturas ético-políticas que muitas vezes não escapam das estratégias de sobrevivência desse sistema sociopolíticoeconômico.

A contribuição de Michel Foucault sobre a questão do conhecimento na modernidade me parece uma ferramenta bastante interessante para a nossa discussão. $\mathrm{O}$ autor fala sobre uma "política do enunciado científico" (FOUCAULT, 2003b), que, ao contrário de direcionar a análise para identificar poderes externos que exercem pressão sobre a ciência (interesses de mercado, de status político, etc.) e 
que conduziriam a produção do conhecimento a partir de fora do conhecimento, trata-se de pensar que esses efeitos de poder circulam dentro do próprio discurso científico, construindo uma mecânica interior de poder que possibilita certos objetos de estudo e não outros. Essa "economia da verdade" (idem) teria cinco características: (1) a verdade é centrada no discurso científico e nas instituições que o produzem; (2) é necessária tanto ao poder econômico quanto ao poder político; (3) é imensamente distribuída e consumida sob várias formas, através dos aparelhos de educação e informação; (4) é difundida sob o controle, não dominante, mas exclusivo, de grandes aparelhos econômicos e políticos; (5) é objeto de debate político e de confronto social (FOUCAULT, 2003b, p. 13).

É importante esclarecer que para o autor há uma estreita relação entre saber, verdade e poder. Saber gera poder e este, por sua vez, produz mecanismos de produção de saber que o legitimam e garantem sua manutenção.

A historicidade da verdade não se daria, segundo o autor, por um processo de mudanças do conhecimento produzido ao longo da história a partir de um jogo de acertos e erros em que se tenta chegar o mais próximo possível da completude do conhecimento por meio de refutações e atualizações das descobertas - mudanças de "conteúdo" -, tampouco por uma alteração dos métodos teóricos - mudanças de "paradigma" (Idem, p. 4).

A verdade não é uma questão de aproximação - de uma essência, de tempo - ou de regionalidade - que varia localmente, mas dentro de uma gama inscrita em uma universalidade (VEIGA-NETO, 2003); a verdade não é "o conjunto das coisas verdadeiras a descobrir ou a fazer aceitar", ela é "o conjunto das regras segundo as quais se distingue o verdadeiro do falso e se distribui ao verdadeiro efeitos específicos de poder" (ibidem, p. 13).

É o que Foucault chama de regime de verdade. O regime - ou vontade - de verdade é o que desenha planos dos objetos possíveis, observáveis, mensuráveis, classificáveis; o que impõe ao sujeito certo olhar, certa posição, certa função; o que prescreve o nível técnico; o que se desloca ao longo das modificações das condições históricas e se 
apóia sobre um suporte institucional, exercendo dessa forma uma pressão e uma coerção sobre os discursos:

[a vontade de verdade] é ao mesmo tempo reforçada e reconduzida por todo um compacto conjunto de práticas como a pedagogia, é claro, como o sistema dos livros, da edição, das bibliotecas, como as sociedades de sábios de outrora, os laboratórios de hoje. Mas ela é também reconduzida, mais profundamente sem dúvida, pelo modo como o saber é aplicado em uma sociedade, como é valorizado, distribuído, repartido e de certo modo atribuído (FOUCAULT, 2001, p. 17).

Ou seja, a disciplina, como discurso científico, é uma forma de controle da produção discursiva. Ela impõe limites ao discurso "pelo jogo de uma identidade que tem a forma de uma reatualização permanente das regras" (idem, p. 36).

É sempre possível dizer o verdadeiro no espaço de uma exterioridade selvagem; mas não nos encontramos no verdadeiro senão obedecendo às regras de uma "polícia" discursiva que devemos reativar em cada um de nossos discursos (ibidem, p. 35).

A verdade é, então, produzida por procedimentos discursivos de controle do próprio discurso, que submetem a dimensão do "acaso"2 e do "acontecimento" do discurso (ibidem, p. 21). Através de seus mecanismos de seleção, a verdade exclui os discursos que não se enquadram em suas regras, em seu regime de verdade (FOUCAULT, 1995; 2001; 2003a; 2003b).

A conceituação de um objeto não tem como critério o "objeto em si", mas antes é regida pelas necessidades conceituais de um determinado período histórico que visam dar conta dos problemas suscitados por ele. Trata-se das motivações históricas que criam um campo epistemológico para a produção do conhecimento em

2 Acaso "não como um simples sorteio, mas como o risco sempre renovado da vontade de potência que a todo surgimento do acaso opõe, para controlá-lo, o risco de um acaso ainda maior" (FOULCAULT, 2003b, p. 28). 
articulação com a rede de possibilidades discursivas para a produção dos enunciados.

Foucault dá o nome de episteme a essa ordem discursiva que define as condições de possibilidade do conhecimento, ou seja, define o que pode e o que não pode ser dito, o que é verdadeiro e o que não é. A episteme não é sinônimo de saber, mas de um princípio de ordenação dos discursos a partir de um mesmo regime de verdade, ela é um dispositivo especificamente discursivo. "A epistémè é a ordem específica do saber; é a configuração, a disposição que o saber assume em determinada época e que lhe confere uma positividade enquanto saber" (MACHADO, 1982, p. 148).

O mecanismo disciplinar, portanto, como dispositivo de formação e de informação do conhecimento, é um dispositivo de subjetivação que busca delimitar critérios de verdade, estabelecendo um campo de saber que torna administrável todo conhecimento produzido, bem como os sujeitos que o produzem ou dele se utilizam, na tentativa de estabelecer a ordem, a homogeneização.

\section{A educação como um processo de subjetivação: que sujeitos queremos produzir? Que meio ambiente queremos ensinar?}

Sendo a educação um processo de subjetivação, devemos questionar que sujeitos queremos em nossa sociedade. Uma educação realizada por meio do dispositivo disciplinar é uma prática territorializadora de indivíduos, ou seja, é uma prática que aprisiona o sujeito nas fronteiras de um molde. Uma educação que trabalhe o tema meio ambiente dessa forma é uma educação que tentará sempre fechar um conceito de ambiente, uma idéia de natureza, uma noção de sujeito e de sociedade. É uma educação que produz discursos reducionistas sobre as questões ambientais - discursos economicistas, discursos biologicistas, etc. Esses discursos não conferem ao tema a complexidade que lhe é devida. A própria idéia que se tem do que é um problema ambiental e de quais deveriam ser nossos julgamentos sobre ele fica comprometida através de uma análise que não se proponha estar sempre aberta a questões ainda não colocadas. 
Isso é característico da subjetividade produzida pela lógica "capitalística", tal como é denominada por Guattari: guiada pelos padrões, pela uniformização, pela universalização e pela dualidade certo/errado, bom/mau, feio/bonito, certeza/incerteza, etc. É uma lógica que acredita na existência de possibilidades únicas: um corpo, uma beleza, um estilo, uma verdade, um comportamento diante de determinada situação, etc. A diferença traduz-se no erro. Segundo Guattari (2001, p. 34),

a subjetividade capitalística, tal como é engendrada por operadores de qualquer natureza ou tamanho, está manufaturada de modo a premunir a existência contra toda intrusão de acontecimentos suscetíveis de atrapalhar e perturbar a opinião. Para esse tipo de subjetividade, toda singularidade deveria ou ser evitada, ou passar pelo crivo de aparelhos e quadros de referência especializados. Assim, a subjetividade capitalística se esforça por gerar o mundo da infância, do amor, da arte, bem como tudo que é da ordem da angústia, da loucura, da dor, da morte, do sentimento de estar perdido no cosmos...

O conhecimento sobre a problemática ambiental produzido pelos discursos científicos construídos dentro uma racionalidade disciplinar é passível, portanto, dos regimes de verdade que regem a subjetividade capitalística e os discursos por ela produzidos. Os conhecimentos sobre a relação homem-natureza veiculados pelo discurso científico são tributários de conflitos entre interesses diversos e de lutas políticas e ideológicas que articulam poder e saber e que configuram discursos nos quais determinados critérios são priorizados em detrimento de outros. Todo discurso sobre as questões ambientais e toda proposta educacional de trabalhar com esse tema carrega consigo uma concepção de meio ambiente, de homem, de sociedade, que é tributária de determinados regimes de verdade e que determina uma certa postura ético-política frente a essas questões.

Se a discussão sobre meio ambiente no espaço escolar é baseada no conhecimento científico de forma a não escapar do estado disciplinar, podemos pensar, então, que fica comprometida toda 
proposta de compreensão desse tema. O olhar sobre o meio ambiente a partir da sobreposição de diferentes disciplinas e de seus diferentes objetos, além de não ser suficiente para o entendimento da multiplicidade de fatores que compõem uma problemática ambiental, acaba, ao mesmo tempo, restringindo a atividade do pensamento por basear-se em uma pré-formatação do conhecimento dividido em "arquivos" científicos, que dirigem a análise de modo a excluir qualquer possibilidade de relação que fuja dos moldes considerados como válidos pelo discurso científico.

\section{As (im)possibilidades do discurso sobre o meio ambiente na escola}

Meio ambiente constitui um dos temas transversais, segundo os Parâmetros Curriculares Nacionais (PCN), formulados pelo Ministério da Educação e do Desporto (MEC), para o ensino fundamental. De acordo com o MEC, a transversalidade de alguns temas sociais tem em vista "contemplá-los em sua complexidade, sem limitá-los à abordagem de uma única área" (BRASIL, 1998, p. 65).

Gostaria de salientar que as motivações que estão por trás do presente trabalho não incluem desqualificar a iniciativa de inserção do tema meio ambiente realizada pelo MEC. Os méritos das propostas realizadas pelos PCN e pelo Programa Parâmetros em Ação - Meio Ambiente na Escola são indiscutíveis simplesmente por serem ações sérias e realmente comprometidas com a tentativa de inserção do tema no ensino brasileiro. As questões que serão aqui levantadas têm como intuito alimentar o debate acerca do tema meio ambiente e educação e contribuir para que o pensamento esteja sempre vivo e atuante, fazendo proliferar ainda mais diferenças.

Partindo da posição explicitada até aqui, proponho uma reflexão primeiramente com base numa questão colocada por Gallo (2002). Discutindo sobre a transversalização da filosofia no currículo escolar, o autor nos alerta para a noção de que "só se pode transversalizar a partir de uma singularidade" (GALLO, 2002, p. 287). Ou seja, para que a filosofia - e podemos aplicar o comentário à nossa questão, que é o 
meio ambiente - atravesse as disciplinas curriculares, é necessário antes de tudo que sua singularidade esteja presente na escola. Isso só é possível a partir de um professor bem formado, apto a trabalhar com o tema, e, conseqüentemente, da existência de uma disciplina de filosofia.

O problema que se coloca é que, contraditoriamente, para que seja possível o desaparecimento de uma configuração disciplinar, uma "desdisciplinarização", será preciso primeiramente que existam as disciplinas. Mesmo com todas as limitações que as disciplinas impõem ao discurso, como já discutido aqui neste trabalho, num panorama em que a configuração disciplinar rege não só a aquisição como também a produção de conhecimentos, será que o meio ambiente necessita constituir-se como uma disciplina curricular para que, a partir desta existência criada no currículo, possa um dia ser transversalizado?

Pensar sobre isso, atualmente, é um tanto polêmico. Há um certo mal-estar acerca das propostas para se confinar a Educação Ambiental (EA) em uma disciplina, seja na educação formal, seja na educação não formal. Recentemente, durante um debate no $V$ Fórum Brasileiro de Educação Ambiental’, um educador colocou uma questão relacionada à inserção da EA como disciplina no currículo escolar, para pensarmos se isso não seria interessante e vantajoso para a área. A reação geral foi tão contrária à sua fala que houve uma manifestação na forma de vaias por parte de alguns presentes.

Contraditoriamente, esse episódio deixa muito claro, a meu ver, o modo disciplinar de operação do campo da EA (MALDONADO, 2001; PALHARINI, 2005). Há um regime de verdade acerca de a EA não ser uma disciplina - discurso que acabou sendo incorporado pelo plano jurídico ${ }^{4}$-, o qual acabou se transformando em "consenso", de forma a fazer com que as divergências, as posições contrárias a isso desapareçam por completo. Mais do que isso, essas divergências são

3 V Fórum Brasileiro de Educação Ambiental, realizado na cidade de Goiânia, em 2004.

4 A Lei no 9.795/99, que dispõe sobre a Política Nacional da Educação Ambiental, em seu Capítulo I, Artigo 3o afirma que as instituições educacionais devem "promover" a Educação Ambiental de maneira "integrada aos programas educativos que desenvolverem" e não como disciplina, salvo exceções no ensino superior. 
transformadas em absurdo, em ridículo, em ingênuo e ultrapassado. "Já passamos desse ponto...", dizem alguns educadores. Mas, quem passou? E os "novos" educadores ambientais que estão chegando na área? Eles não estão autorizados a pensar fora dessa ordem do discurso, a resgatar "velhas" concepções dos entulhos? Com o tempo, aquilo que não mais se diz passa a não existir; do que não existe não é necessário que se fale.

A segunda questão para a qual chamo a atenção é a transversalização, tal como foi adotada pelo MEC para o ensino fundamental, a qual pode não representar a possibilidade de mudanças significativas para o currículo e a produção de saber no espaço escolar. Isso porque os temas encontram-se ainda preordenados por uma sistematização disciplinar que apenas coloca em contato diferentes áreas do conhecimento, sem fazer desaparecer suas fronteiras. Como afirma Grisotto (2002, p. 78-79):

as questões urgentes dos temas transversais já se encontram pré-formatadas por uma ordem disciplinar com fortes relações com a ordem capitalista já existente e que estaria, por este motivo, mais propícia a filtrar, organizar, sistematizar, capturar, ao menos no discurso, toda iniciativa mais espontânea (...). Assim, os temas transversais não representariam uma inovação aberta à problematização da ética, às iniciativas em prol do meio ambiente, à valorização da pluralidade cultural, etc., mas formas de dar a estes mesmos assuntos um direcionamento, reduzindo-os ao estatuto em que podem ser controlados, redimensionados, para que se aperfeiçoando na e para a ordem, permitam, a esta mesma ordem, a sua apropriação (...).

Vejo claramente uma ótima intenção, mas uma certa confusão metodológica permeando as propostas. O próprio caderno de atividades do Programa Parâmetros em Ação - Meio Ambiente na Escola, que se propõe como um caderno de "sugestões" (BRASIL, 2001b, p. 14) de atividades, recebe o título de Guia de Atividades para Sala de Aula e indica, até mesmo, as disciplinas que podem trabalhar cada atividade sugerida ao invés de deixá-las em aberto para que cada professor crie a partir dos temas independentemente de sua formação e da disciplina pela qual é responsável. 
Além disso, os discursos freqüentemente veiculados são muito repetidos, mas nem sempre questionados: a vontade de uniformização de uma EA é clara e a problemática ambiental carece de um olhar político que coloque em cena a polêmica e a complexidade presentes nas diversas situações.

No Caderno de Apresentação do Programa Parâmetros em Ação Meio Ambiente na Escola (BRASIL, 2001a, p. 23), isso já pode ser percebido. A seguir, destaco um trecho:

Desde o início, as propostas de Educação Ambiental se posicionaram contra o modelo de ensino baseado na transmissão de conteúdos fragmentados, que não se inter-relacionam e não têm referência nas experiências e vivências dos próprios alunos. A proposta dos parâmetros e referenciais curriculares introduziu mudanças nesse quadro, ao colocar entre os objetivos do ensino fundamental a necessidade de tornar os alunos capazes de:

- compreender a cidadania como participação social e política, assim como exercício de direitos e deveres políticos, civis e sociais, adotando no dia-a-dia atitudes de solidariedade, cooperação e repúdio às injustiças, respeitando o outro e exigindo para si o mesmo respeito;

- posicionar-se de maneira crÍtica, responsável e construtiva nas diferentes situações sociais, utilizando o diálogo como forma de mediar conflitos e de tomar decisões coletivas.

- Atingir esses objetivos, que se coadunam com as propostas da Educação Ambiental, é um grande desafio para os educadores.

Destaco alguns pontos desse trecho:

1) Inter-relacionar os assuntos não significa transversalizar os assuntos da forma como entendo que seja uma transversalidade. A inter-relação coloca em diálogo diferentes disciplinas, estreitando a distância entre elas e fazendo valer uma noção de pluralidade da realidade. A transversalidade faz desaparecer as fronteiras das disciplinas (GALLO, 2002), evidenciando a construção em rede do 
conhecimento e apontando para uma noção de multiplicidade. Se a pluralidade traz a idéia das várias realidades, a multiplicidade traz a idéia de que não existe uma realidade e que a partir de uma determinada perspectiva uma nova questão pode surgir e reterritorializar todo o meio ali cartografado.

2) A transmissão fragmentada de conteúdos é de ordem epistemológica e metodológica; o enfoque à cidadania e participação social e política, bem como à criticidade e responsabilidade social, é de ordem político-filosófica. Portanto, não é possível haver mudança do modelo de ensino fragmentado pelo ensino da cidadania. Este último pode-se dar, inclusive, de forma fragmentada também.

A EA da forma como é proposta pelo MEC é, ainda, normativa e centralizada na conduta e na responsabilidade e ética individuais. Provoca incoerências ao especificar, por exemplo, que entre os objetivos está o de tornar os alunos capazes de ter atitudes de "repúdio" às injustiças através do "respeito" ao outro, ferindo sem perceber princípios inerentes a muitas propostas da EA, como a valorização das diferenças. Territorializa um posicionamento diante do tema ao prescrever uma série de condutas ecológica e politicamente corretas, mesmo que suas intenções sejam as de enfatizar a responsabilidade de todos os cidadãos perante tais questões. Acaba por centralizar a questão da responsabilidade individual como um dos maiores alicerces da problemática ambiental, atuando ainda dentro do discurso da "conscientização".

O olhar sobre as questões ambientais a partir dessa proposta é ainda um olhar fragmentado, mesmo que seja interessante por não restringir o tema a uma única disciplina - no caso, a de Ciências. Mas a análise da problemática ambiental continua a se organizar em "gavetas", que podem ser abertas no momento em que se quiser discutir sob esse

\footnotetext{
5 Pergunto: será mesmo pela consciência que passam as questões ambientais? Há hoje quem defenda a "sensibilização" ambiental em lugar da "conscientização". A conscientização na história do pensamento ocidental está ligada a uma concepção de verdades universais, essenciais. Foucault (1985) desloca o eixo "consciênciaconhecimento-ciência" para "formações discursivas-saberes-ciência", a fim de desfazer a pretensão de todo conhecimento de ser verdadeiro e científico para ganhar um status de validade.
} 
ou aquele aspecto; a partir da história do desmatamento de uma região ou de seus impactos sobre a fauna e a flora ou do empobrecimento em nutrientes químicos do solo, etc. E, mesmo que seja feita a tentativa de junção dos diferentes aspectos com um $e$, não avançamos para além de uma sobreposição de partes; de "somar as partes para formar o todo".

Para finalizar, não basta, portanto, juntar as partes para se tentar compreender uma problemática ambiental. A posição que prefiro tomar é a de que o "todo" é um território aberto e instável, é uma gama de diversas possibilidades de combinações entre os elementos que o constituem e que ora territorializam um mapa, ora desterritorializam-no para reterritorializar um outro diferente (idem). Uma problemática ambiental não é composta por um número de causas finitas que operam de forma disciplinar - nos dois sentidos da palavra, o da ordem e o da organização sistemática do conhecimento -, mas por configurações que operam também de forma caótica, rizomática (DELEUZE e GUATTARI, 1995), em uma rede de relações.

É preciso que nós, educadores ambientais, tenhamos a disponibilidade para mergulhar nesse caos, para a partir dele traçar entendimentos e propor uma educação que desperte uma multiplicidade de atitudes de transformação da relação homem-ambiente num momento presente e futuro na história do pensamento ocidental. Uma educação que se abra sempre para o novo, que assuma sua finitude e suas limitações, sua historicidade como acontecimento; que não se faça por um discurso do "ecologicamente correto", não uniformize desejos em nome de um "meio ambiente" abstrato e instituído pela mídia capitalística.

Vivemos em espaços "maiores" e "menores", segundo Deleuze e Guattari (1997, p. 19): as malhas do Estado e as da máquina de guerra. É preciso, antes, esclarecer que, para esses autores, o Estado não se reduz a aparelhos e aos representantes que neles atuam, ele não se define "pela existência de chefes, mas sim pela perpetuação e conservação de órgãos de poder" distintos do corpo social.

Ou seja, o Estado é uma forma de operação do poder que se dá por um movimento "estriado" (idem), que opera por "linhas" e "segmentos", por espaços estruturados, institucionalizados, legitimados pela sociedade 
(DELEUZE e GUATTARI, 1996, p. 95). A máquina de guerra, ao contrário, opera por movimentos "lisos" (DELEUZE e GUATTARI, 1997) que percorrem espaços invisíveis, indefinidos, não estruturados, não previsíveis pelo movimento Estado. Os primeiros movimentos são responsáveis por uma certa ordenação das práticas (Estado), os segundos levam à multiplicação das diferenças (máquinas de guerra).

Para os autores, esses dois modos de operação do poder, centralizados em órgãos específicos e dispersos no corpo social, não existem em termos de independência de um em relação ao outro, mas de "coexistência" e de "concorrência", "num campo perpétuo de interação" entre as máquinas de guerra de metamorfose e os aparelhos identitários de Estado (idem, p. 24). "Um mesmo campo circunscreve sua interioridade em Estados, mas descreve sua exterioridade naquilo que escapa aos Estados ou se erige contra os Estados" (ibidem).

Sob essa perspectiva, podemos pensar que o campo da EA existe através desses dois movimentos. Há a delimitação de fronteiras, identidades, princípios, leis, os mecanismos disciplinares de Foucault, os discursos "ultrapassados" da EA. Mas essas maquinarias disciplinares não dão conta de realizar um controle total: as práticas em EA extravasam qualquer maquinaria identitária, fazem proliferar metamorfoses dessa EA instituída que escapa a qualquer identidade. A EA como campo que quer instituir-se, ganhar visibilidade, legitimidade necessita da forma Estado, é ela quem lhe garante lugar nos espaços instituídos, disciplinares - Ministérios, políticas públicas, escola, encontros nacionais e internacionais, decisões jurídicas em situações de conflito, etc. Mas é também através de suas metamorfoses que ela se torna possível, viva, dinâmica, hábil o suficiente para penetrar ainda mais nas malhas estriadas, mudando leis, propondo novos valores, reivindicando direitos de classe, formando redes que adquirem um lugar próprio na disputa com outros discursos da sociedade.

Uma EA que aposte nessa perspectiva, de ver os dois movimentos como partes constituintes de seu acontecimento, é aquela que não se vê como imprescindível, como fruto do amadurecimento de uma árvore do conhecimento que deve ser transmitida a toda a humanidade. Tem lucidez o suficiente para não ser uma EA que 
prescreve condutas morais, e sim uma educação comprometida com a não pretensão de transformar seus educandos em conservação do mesmo, com discursos gastos e cansados.

Penso que, antes de tudo, nós, educadores ambientais, temos que abrir mão do poder da verdade do meio ambiente. É preciso estar aberto ao risco e ao desapego dos saberes que se quer ensinar e pelos quais se quer lutar. Afirmá-los como verdade nos faz colocar um sistema homogêneo no lugar de outros. É preciso ver nesse movimento da EA algo diferente do que seria a posse de alguns sobre a verdade do meio ambiente. Isso não significa de forma alguma abdicar daquilo em que se acredita e daquilo que se quer ensinar. Não se trata de um valetudo em lugar de um "vale-nada". Trata-se apenas de não ter nenhuma garantia definida previamente, pois não há nada que assegure uma verdade, a não ser as relações de poder que em torno dela se travam.

Talvez seja preciso opor resistência não somente aos discursos contrários ao meio ambiente como também a qualquer discurso ambiental que se afirme como uma tradição forçada. Desconfiar de toda instituição ${ }^{6}$ generalizante, uniformizante em nome de quem quer que seja. Permitir uma educação que não se baseie somente em ações e planejamentos predefinidos, preparados, mas que seja aberta ao risco de ser confrontada: relação pedagógica como uma batalha entre diferentes e não como submissão de um - educando - ao outro - educador (ou vice-versa). Não é necessário fugir da busca de uma identidade do meio ambiente ou da educação ambiental. Os mapas podem ser traçados, mas é preciso que não se cristalizem. É preciso extrair a identidade das diferenças e não o contrário.

Faço minhas as palavras de Bruno Latour (2002):

As diferenças existem não para serem respeitadas, ignoradas ou subsumidas, mas para servirem de isca aos sentimentos, de alimento para o pensamento.

6 Instituição, segundo Foucault (2003b, p. 247), é "todo comportamento mais ou menos coercitivo, aprendido. Tudo que em uma sociedade funciona como sistema de coerção, sem ser um enunciado, ou seja, todo o social não discursivo é a instituição". 


\section{Referências bibliográficas}

BRASIL. Parâmetros Curriculares Nacionais: terceiro e quarto ciclos do ensino fundamental: introdução aos parâmetros curriculares nacionais. Brasília: MEC/SEF, 1998.

BRASIL. Programa Parâmetros em Ação - Meio Ambiente na Escola: Caderno de Apresentação. Secretaria de Educação Fundamental. Brasília: MEC; SEF, 2001.

BRASIL. Programa Parâmetros em Ação - Meio Ambiente na Escola: Guia para atividades em sala de aula. Secretaria de Educação Fundamental. Brasília: MEC; SEF, 2001.

CARVALHO, Isabel Cristina de Moura. Educação Ambiental Crítica: nomes e endereçamentos da educação. In: Identidades da Educação Ambiental Brasileira. Brasília: Ministério do Meio Ambiente, 2004.

DELEUZE, Gilles e GUATTARI, Félix. Rizoma. In: Mil platôs: capitalismo e esquizofrenia. v. 1. $1^{\text {a }}$ edição. $1^{\mathrm{a}}$ reimpressão - 1996. São Paulo: Editora 34, 1995.

. Micropolítica e segmentaridade. In: Mil platôs: capitalismo e esquizofrenia. v. 3. $1^{\mathrm{a}}$ edição. $1^{a}$ reimpressão - 1999. São Paulo: Editora 34, 1996.

. Tratado de Nomadologia: a Máquina de Guerra. In: Mil platôs: capitalismo e esquižofrenia. v. 5. $1^{\text {a }}$ edição. $1^{\text {a }}$ reimpressão - 2002. São Paulo: Editora 34, 1997.

FOUCAULT, Michel. As palavras e as coisas: uma arqueologia das ciências humanas. $3^{\mathrm{a}}$ ed. São Paulo: Martins Fontes, 1985.

. O sujeito e o poder. In: DREYFUS, Hubert; RABINOW, Paul. Michel Foucault: uma trajetória filosófica - para além do estruturalismo e da hermenêutica. Rio de Janeiro: Forense Universitária, 1995.

. A ordem do discurso. $7^{\mathrm{a}}$ ed. São Paulo: Edições Loyola, 2001.

- História da sexualidade I: a vontade de saber. $15^{\mathrm{a}}$ edição. Rio de Janeiro: Edições Graal, 2003a. 
- Microfísica do poder. Rio de Janeiro: Edições Graal, 2003b.

GALLO, Sílvio. Conhecimento, transversalidade e educação: para além da interdisciplinaridade. Impulso, 1997.

Filosofia e educação: pistas para um diálogo transversal. In: KOHAN, Walter O. (org.). Ensino de filosofia. Belo Horizonte: Autêntica, 2002.

GRISOT'TO, Américo. Parâmetros curriculares nacionais: uma abordagem epistemológica das questões éticas. Campinas, 2002. (Dissertação de mestrado apresentada à Faculdade de Educação/ Unicamp)

GUATTARI, Félix. As três ecologias. 11ª ed. Campinas: Papirus Editora, 2001.

GRÜN, Mauro. Ética e Educação Ambiental: a conexão necessária. Campinas, SP: Papirus, 1996.

LATOUR, Bruno. Reflexão sobre o culto moderno dos deuses fe(i)tiches. Bauru/ SP: EDUSC, 2002.

MACHADO, Roberto. Ciência e saber. Rio de Janeiro: Edições Graal, 1982.

MALDONADO, Maritza. A ordem do discurso da educação ambiental. Dissertação (Mestrado em Educação) - Universidade Federal do Rio Grande do Sul, Porto Alegre, 2001.

MORIN, Edgar. Ciência com Consciência. Rio de Janeiro: Bertrand Brasil, 2000.

PALHARINI, Luciana. A Educação Ambiental enquanto campo de conbecimentos: fatos ou fetiches? Campinas, 2005. (Dissertação de mestrado apresentada à Faculdade de Educação/ Unicamp).

SANTOS, Boaventura de Sousa. A crítica da razão indolente: contra o desperdício da experiência. São Paulo: Cortez, 2000. 
SOFFIATI, Arthur. Fundamentos filosóficos e históricos para o exercício da ecocidadania e da ecoeducação. In: LOUREIRO, Carlos Frederico B.; LAYRARGUES, Philippe P.; CASTRO, Ronaldo Souza de (org.). Educação ambiental: repensando o espaço da cidadania. São Paulo: Cortez Editora, 2002.

VEIGA-NETO, Alfredo J. Ciência e Educação Ambiental em um cenário pósmoderno. Rio Grande do Sul: Revista Educação \& Realidade, 19(2):141- 169, 1994.

Foucault \& a Educação. Belo Horizonte: Autêntica, 2003. 